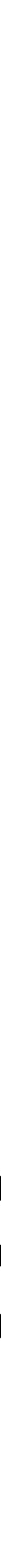




\title{
Sobre a crítica radical de Ser e tempo à noção metafísica de consciêncial
}

\author{
Rafael Ribeiro de Almeida ${ }^{2}$ \\ Universidade Estadual de Santa Cruz
}

\begin{abstract}
1. Uma versão inicial do presente artigo, com título diferente, foi apresentada no XXII Encontro Nacional de Pesquisa na Graduação em Filosofia da USP, realizado no Departamento de Filosofia no período de 22 a 26 de abril de 2019, na FFLCH-USP.

2. Registro meus agradecimentos aos pareceristas anônimos pelas indicações teóricas e pertinentes comentários que foram decisivos para a finalização deste artigo
\end{abstract}

RESUMO: O texto desenvolvido pretende examinar a forma originária de Martin Heidegger de abordar o fenômeno da consciência, em contraponto a esta noção segundo o paradigma da metafísica moderna. Para tanto, investiga-se o pensamento heideggeriano em sua primeira fase, especialmente Ser e tempo, de 1927. Na obra, o filósofo alemão situa a consciência, em primeiro lugar, como fenômeno existencial que, enquanto tal, enraíza-se no ser-no-mundo. Desse modo, nota-se explícita contraposição ao modelo paradigmático que fundamenta a separação sujeito-objeto ou consciência-mundo, cujo filósofo emblemático está René Descartes. Ao cabo, o fenômeno da consciência que, por excelência, é existencial, encontra-se radicado na própria constituição fundamental do Dasein de ser-no-mundo, na medida em que visa recuperar o seu poder-ser-si-mesmo, isto é: existência autêntica.

PALAVRAS-CHAVE: consciência; Ser e tempo; existência; ser-no-mundo; poder ser si mesmo. 


\section{CONSIDERAÇÕES INTRODUTÓRIAS}

Ser e tempo lança uma virada paradigmática na história da filosofia. O tratado de 1927 procura situar o fenômeno da consciência enquanto radicada existencialmente no ser-no-mundo. Com isso, Heidegger contrapõe-se ao modelo filosófico que fundamenta a separação consciência-mundo. Em lugar do ideal do pensamento puro, o filósofo alemão busca conceber a consciência, inicialmente, como um fenômeno por excelência existencial e, por isso mesmo, enraizado no ser-no-mundo já que, no limite, ela visa recuperar o modo de ser autêntico do Dasein.

No primeiro item ("Ser e tempo e a inauguração de um paradigma”), pretendemos contrapor o paradigma inaugurado por Ser e tempo, com aquele em que as teorias da relação sujeito-objeto se baseiam. René Descartes pode ser apreendido como figura emblemática quanto ao modelo filosófico que fundamenta o dualismo sujeito-objeto'. Inicialmente, o filósofo fundamenta essencialmente o homem como substância pensante, res cogitans. Com isso, traz à tona umas das principais novidades filosóficas da modernidade: a subjetividade, o sujeito, o eu como o grande polo fixo constituinte da verdade. A filosofia cartesiana da subjetividade, neste sen-

1. "Descartes é um alvo privilegiado da crítica heideggeriana” (STEIN, 2005, p. 25). 
tido, explicita uma separação ontológica entre consciência e mundo, ou sujeito e objeto: de um lado, consciência interiorizada e encapsulada, de outro lado, objeto externo simplesmente dado - eis, então, o modelo para as teorias da representação. A fim de problematizar a relação subjetividade-objetividade, Heidegger traz à luz, em Ser e tempo, a constituição fundamental do Dasein enquanto ser-no-mundo. Diferente do paradigma segundo o qual há separação ontológica entre consciência e mundo, o Dasein não está "fora" ou "sobre" o mundo, mas o mundo é uma questão do Dasein. Como ser-no-mundo, o Dasein sempre esteve "no" mundo, ou, o que significa em última instância o mesmo: em sendo, o Dasein já está-no-mundo. Esta é a condição originária do Dasein: ser desde sempre junto-ao-mundo.

No segundo item ("Consciência enraizada no ser-no-mundo"), pretende-se examinar a noção de consciência na obra capital de Heidegger. Ser e tempo inaugura uma virada paradigmática na história da filosofia: aborda a consciência como que enraizada no ser-no-mundo. A consciência radica-se no ser-no-mundo na medida em que implica no si-mesmo em sentido próprio enquanto modo de ser do Dasein. É através da consciência - ao apelar e ao mesmo tempo compreender o clamor desse apelo - que o Dasein, ao querer-ter-consciência, pode ser a partir de si-mesmo. O que está em jogo com o poder-ser-si-mesmo é a possibilidade de o Dasein assumir seu próprio ser - sendo-no-mundo, portanto, em sentido próprio.

\section{SER E TEMPO E A INAUGURAÇÃO DE UM PARADIGMA}

Segundo o Dicionário de Filosofia, a palavra "paradigma" ou "paradigmático" tem um sentido de “exemplo', 'amostra', 'padrão', 'modelo', 'cópia”" (MORA, 2000, p. 2199). Quer dizer, paradigma está enquanto modelo filosófico dentro do qual se desenvolvem (e recebem fundamentação) os concei- 
tos e as teorias de determinados pensadores (MORA, 2000). Nesse sentido, René Descartes sedimenta de forma emblemática o paradigma que fundamenta o dualismo sujeito-objeto. Isto se deve, inicialmente, à ambiciosa empreitada que o filósofo francês propõe-se como projeto, a saber: levar o "homem" à verdade totalizante do mundo. Se é assim, porém, não há como deixar de indagar: o que o autor tem em vista, afinal, com o termo "homem"?

Descartes fundamenta a essência do ente humano a partir do ato de conhecer racionalmente. Segundo diz, a razão, ou a consciência (seu sinônimo), que todos os homens têm de maneira igual, significa "o poder de bem julgar e distinguir o verdadeiro do falso" (DESCARTES, 1983, p. 29). Além disso, nossa imaginação ou os nossos sentidos sensíveis só podem nos assegurar alguma coisa de certo, se o nosso entendimento, necessariamente, intervier. Nota-se, então, no que diz respeito ao nosso saber, que desde os fundamentos primeiros até seus corolários e desdobramentos conclusivos, o que temos o tempo todo é o trabalho constituinte da razão.

Indo além, Descartes faz da razão um apanágio do ente humano, ao colocá-la como "a única coisa que nos torna homens e nos distingue dos animais" (DESCARTES, 1983, p. 29). Vê-se que o autor define o homem, por assim dizer, como um ser essencialmente/substancialmente dotado de razão: "compreendi por aí que era uma substância cuja essência ou natureza consistia apenas no pensar" (DESCARTES, 1983, p. 47) - ou seja: Descartes define-o como substância pensante, res cogitans.

Com isto, o filósofo do cogito realiza uma das principais inaugurações da modernidade, a saber, a subjetividade, o sujeito, o eu. No Discurso do Método, ele diz: "notando que esta verdade: eu penso, logo existo, era tão firme (...), julguei que podia aceitá-la, sem escrúpulo, como o primeiro 
princípio da filosofia que procurava" (DESCARTES, 1983, p. 46, grifo nosso). Já na Meditações Metafísicas, na segunda meditação, ele destaca que a primeira certeza e a mais indubitável a qual inaugurará toda uma cadeia de razões reside no Eu-existente - este é o conhecimento mais certo e mais evidente do livro em questão (DESCARTES, 2005). Através do movimento que parte do interior (eu) para o exterior (mundo), o sujeito passa a ser o grande polo fixo constituinte da verdade.

Contudo, o que nos garante, afinal, que este movimento nos leve, de fato, à verdade? Quer dizer, porque é certo que o eu, res cogitans, possa coincidir com a verdade?

A estas indagações pode-se responder, com base em Descartes, que nossas ideias têm fundamento de verdade porque possuem procedência divina: "e por que tudo que existe em nós nos vem dele [Deus]" (DESCARTES, 1983, p. 50). Se Deus (res infinita) existe como ser infinito e perfeito, bom e veraz, não pode permitir, pois, o erro sistemático do espírito humano. Diferente de um gênio maligno (malin génie), Deus é bom e veraz (bon Dieu), o que garante, assim, o otimismo da nossa crença na razão. Substituindo o malin génie pelo bon Dieu, Descartes pode afirmar seguramente que conhecer pode corresponder à verdade.

Observa-se, com isso, o otimismo racionalista que pressupõe a clareza subjetiva correspondente à verdade objetiva. Neste sentido, o racionalismo cartesiano afirma que o subjetivo (o eu pensante) pode corresponder ao objetivo (verdade). Em suma:

As características fundamentais da doutrina cartesiana podem ser recapituladas do seguinte modo: $1^{\mathrm{a}}$ a consciência não é um evento ou um grupo de eventos particulares, nem um aspecto particular ou uma atividade particular da alma, mas é toda a vida espiritual do homem em todas as suas manifestações, desde sentir até raciocinar e querer; $2^{a}$ sua esfera, portanto, é a mesma do eu como sujeito ou substância pensante; $3^{\mathrm{a}}$ ela é auto-evi- 
dência existencial do eu ou, se preferir, o eu é, para ela, a evidência de sua própria existência. (...) Esses pontos básicos serviram como ponto de partida para a filosofia moderna; e, entre eles, aquele que, de certo modo, resume todos os outros, ou seja, a $2^{\mathrm{a}}$, determinou a corrente subjetivista dessa filosofia (ABBAGNANO, 1998, p. 188).

Posto isso, entende-se ao menos parcialmente o quanto o projeto cartesiano é decisivo no tocante à sedimentação do paradigma que fundamenta o dualismo sujeito-objeto. A filosofia da subjetividade de moldes cartesianos acaba por inaugurar e, ao mesmo tempo, ser um arquétipo da modernidade filosófica iniciada cronologicamente no século XVII, que, através de diferentes nomes, persegue racionalmente, de um jeito ou de outro, vários pontos já então almejados pelo filósofo do cogito. Neste sentido, alguns nomes sugerem maior expressividade: Francis Bacon, Baruch Espinoza, Gottfried Leibniz, Nicolas Malebranche. Não só pela proximidade cronológica do século XVII, mas, sobretudo, pela proximidade conceitual, em que, dialogando entre si, tais pensadores dedicaram-se sobre àquela que talvez seja a principal novidade filosófica da modernidade: o eu, sujeito, subjetividade.

Eis, assim, o modelo da teoria da consciência, da relação sujeito-objeto: o primeiro considerado como um "eu puro", interioridade encapsulada em uma "consciência", e o segundo enquanto objeto externo simplesmente dado. O sujeito é uma interioridade que se encontra espacialmente dentro de um continente (mundo). Nota-se que o significado de consciência nesta perspectiva diz respeito a uma relação puramente privada do homem consigo mesmo, na qual ele se desliga do objeto externo e, por isso, retorna para si mesmo. Quer dizer, consciência, nessa acepção filosófica, diz respeito a uma relação "interior" ou "espiritual" supostamente intrínseca ao homem, pela qual ele pode se conhecer de modo privilegiado e assim julgar-se de forma segura. Essa definição de consciência, portanto, corresponde à es- 
fera da interioridade: "o reconhecimento de uma realidade interior privilegiada só existe nas filosofias que assumem como tema a oposição entre 'interioridade' e 'exterioridade'” (ABBAGNANO, 1998, p. 186). Aqui, uma consciência lança seu olhar para o mundo, objeto externo, e projeta uma representação sobre essa exterioridade. Trata-se, então, de um paradigma segundo o qual há explicita separação ontológica entre intelecto e coisa, sujeito e objeto, consciência e mundo.

$* * x$

Com efeito, o pensamento heideggeriano, notadamente nos anos 20, lutou veementemente contra o modelo da relação sujeito-objeto: "Aqui se apresenta a questão paradigmática na qual é substituída a relação com o mundo através da consciência e da representação que sempre chegam tarde" (STEIN, 2005, p. 17). De saída, Heidegger problematiza a suposta separação sujeito-objeto, consciência-mundo:

Como este sujeito que conhece sai de sua "esfera" interna e chega a uma "outra" esfera, a "externa"? Como o conhecimento pode ter um objeto? Como se deve pensar o objeto em si mesmo de modo que o sujeito chegue por fim a conhecê-lo, sem precisar arriscar o salto numa outra esfera? Nesse ponto de partida com suas múltiplas variações, abre-se mão continuamente de questionar o modo de ser do sujeito que conhece, embora, sempre, ao se tratar de seu conhecimento, esse modo de ser esteja implícito. (...) Reina um grande silêncio sobre o que significa positivamente o "interior" da imanência em que o conhecimento está, de início, trancado, e como o caráter ontológico deste "estar dentro" do conhecimento se funda no modo de ser do sujeito. (HEIDEGGER, 1988, p. 99)

Uma vez rompido drasticamente com o paradigma da tradição metafísica, na qual Descartes, por exemplo, concebia o homem como coisa 
pensante, na analítica heideggeriana, diferente disso, o homem não é nem res (coisa) e tampouco cogitans (pensante): mas sim ser-no-mundo - "é assim que o filósofo liquida com a definição metafísica de homem, o homem apenas referido na auto-reflexão. A auto-reflexão surge com o fato de ser-no-mundo" (STEIN, 2005, p. 96). A fim de criticar o então inatacável primado da relação subjetividade-objetividade que, para Heidegger, é tão verdadeira quanto vã, o autor de Ser e tempo traz à tona a constituição fundamental do Dasein de ser-no-mundo: "o ser-no-mundo constitui uma armação rígida dentro da qual se desenrolam as possíveis atitudes e comportamentos do Dasein com seu mundo, sem que se altere ou mesmo se toque na estrutura ontológica da própria ‘armação'” (HEIDEGGER, 1988, p. 238). Neste sentido, acessar Ser e tempo abordando-o no velho paradigma (de matriz cartesiana) significa impedir o próprio acesso às teses centrais da obra.

Como ser-no-mundo, o Dasein não sai de uma consciência interna "encapsulada" e isolada, antes, porém, desde sempre esteve "fora", isto é, sempre esteve "no" mundo, que por isso mesmo sempre foi de alguma forma descoberto pelo Dasein: "O novo paradigma mostra o ser-no-mundo de onde apenas então emerge a consciência” (STEIN, 2005, p. 44). Diferente da subjetividade cartesiana, o mundo não se "abre" para o Dasein, visto que nunca esteve "fechado" para ele. Neste sentido, a relação consciência-mundo de caráter cartesiano é vista por Heidegger como sem fundamento:

Por mais que, do ponto de vista ôntico, essa oposição esteja presa a tantas derivações de conteúdo, a falta de clareza de seus fundamentos ontológicos e dos próprios membros da oposição radica-se diretamente nessa distinção efetivada por Descartes. Dentro de que compreensão ontológica Descartes determinou o ser destes entes? (HEIDEGGER, 1988, p. 135, grifo nosso). 
Na medida em que o Dasein confere abertura a seu ser, ele já está-no-mundo. Com isso, observa-se o corolário segundo o qual, do ponto de vista ontológico, só há "Mundo" porque Dasein existe/abre-se, e Dasein existe/ abre-se porque há "Mundo". A expressão "ser-no-mundo" designa um existencial, por excelência, unitário e indivisível, de sorte que não há Dasein sem mundo (pois só "é" no mundo) e não há mundo sem Dasein (NUNES, 2004) ou, dito nas palavras do próprio autor:

De fato, apenas enquanto o Dasein é, ou seja, a possibilidade ôntica de compreensão do ser, "dá-se" ser. Se o Dasein não existe, também nem "independência" nem "em si" podem "ser". (...) O ente intramundano também não poderia ser descoberto nem permanecer oculto. Então nem se poderia dizer que o ente é ou não é. Agora pode-se realmente dizer que, enquanto houver compreensão do ser e com isso compreensão do ser simplesmente dado, então o ente prosseguirá a ser. (HEIDEGGER, 1988, p. 279, grifo do autor)

Em corroboração à ideia, Stein assinala:

O filosofema "ser-no-mundo" torna-se o tópos hegemônico a partir do qual se inaugura o novo paradigma (com a expulsão de Deus e a forclusão do mundo, da filosofia), ruptura dos modelos que conduzem a tradição: só dá-se ser, só há mundo, só há verdade, se existe o estar-aí. (STEIN, 2005, p. 49)

Em sendo, o Dasein já está-no-mundo. Diferente das entidades desprovidas da estrutura do "ser-no-mundo" que estão, na verdade, "dentro" do mundo, o Dasein está "no" mundo, isto é, Dasein é mundano - o termo mundanidade está exclusivamente como adjetivo do modo de ser do Da$\operatorname{sein}^{2}$. Assim, ser-no-mundo não é uma propriedade que Dasein ora apre-

2. De acordo com Ser e tempo, o sentido de estar "dentro de" caracteriza tão somente a determinação categorial do ente intramundano, como a água está no copo, a roupa está no armário, a sala está na universidade. "Esses entes, que podem ser determinados como estando um 'dentro' do outro, têm o 
senta ora não - não se trata de uma relação que Dasein tem com o mundo. Diferente do paradigma segundo o qual há separação ontológica entre consciência e mundo, o Dasein não está "fora" ou "sobre" o mundo, mas o mundo é em si mesmo um constitutivo do Dasein, de modo que a expressão ser-no-mundo, já em sua composição, dirige-se a um fenômeno de unidade e não de fragmentação de mais de um elemento (o "ser" "no" "mundo"). Em sendo, o Dasein já está-no-mundo, ele só é como é, sendo-no-mundo, quer dizer: a condição originária do Dasein consiste em estar desde sempre junto-ao-mundo.

\section{CONSCIÊNCIA ENRAIZADA NO SER-NO-MUNDO}

Com efeito, Ser e tempo inaugura uma forma nova de conceber e situar o fenômeno da consciência. Mas, indaga-se: em que sentido o tratado em questão concebe e situa o fenômeno da consciência? Ora, é sabido que Heidegger não se notabilizou na história do pensamento por realizar uma "filosofia da consciência", como observa o pesquisador Ronaldo Manzi, no artigo "O que seria a consciência na fenomenologia heideggeriana?”. Aliás, Heidegger sequer realizou uma "filosofia da consciência" e tampouco conferiu um lugar explicitamente privilegiado ao fenômeno em questão: "Obviamente que encontramos um 'papel' para a consciência em Heidegger, mas o fato dela figurar em sua ontologia não nos dá o 'direito' de sugerir que ele está realizando uma 'filosofia da consciência'” (MANZI, 2016, p. 196) $)^{3}$.

Em que sentido, então, os 83 parágrafos de um tratado incompleto não só trazem à tona a consciência, como a concebem de maneira originá-

mesmo modo de ser do que é simplesmente dado, como coisa que ocorre 'dentro' do mundo" (HEIDEGGER, 1988, p. 91-92).

3. Diga-se de passagem, de fato é relativamente escassa a literatura em nível nacional a respeito da noção de consciência em Heidegger. 
ria, e por isso nova, diferenciando-se deste modo da metafísica moderna?

Ser e tempo lança uma maneira mais originária de abordar o fenômeno da consciência, concebendo-a não mais como fundamento das teorias da subjetividade. Antes, porém, o tratado procura situar a consciência enquanto radicada existencialmente no ser-no-mundo. Neste sentido, Stein (2005, p. 32) observa: "a proposta de superação da relação sujeito-objeto, base das teorias da consciência, preparam, portanto, em Heidegger, a mudança do paradigma tradicional e a proposta de uma nova questão do método".

Em primeiro lugar, é preciso evitar uma confusão conceitual e terminológica sobre o sentido que Heidegger tem em mente quando ele se refere à palavra Gewissen, em português consciência. De acordo com o Dicionário de Filosofia, de autoria de Ferrater Mora:

O termo "consciência" tem pelo menos dois sentidos: 1) consideração ou reconhecimento de algo, seja de algo exterior, como um objeto, uma qualidade, uma situação etc., ou de algo interior, como as modificações experimentadas pelo próprio eu; 2) conhecimento do bem e do mal. O sentido 2) é expresso mais propriamente por meio da expressão "consciência moral". (...) Em alguns idiomas, empregam-se termos diferentes para os dois sentidos mencionados: por exemplo, Bewusstsein, Gewissen (em alemão), consciousness, conscience (inglês), respectivamente. (MORA, 2000, p. 550, grifo nosso)

Em consonância com a citação (acima), o idioma alemão diferencia terminologicamente Bewusstsein, enquanto reflexão de um "eu" sobre si mesmo, e Gewissen, cujo sentido é ter consciência do bem e do mal. No segundo termo há uma valoração moral sobre a qual se fala de "voz da consciência".

Em Ser e tempo, Heidegger recusa veementemente a noção de Bewusstsein ${ }^{4}$ diferente de outros pensadores da tradição filosófica que pri-

4. Segundo o Dicionário de Psicologia: "Fora de seu significado moral, a consciência, como observa 
vilegiam o sentido desse termo). Por isso que a investigação de Heidegger evita vias interpretativas que reconduzam à definição de "consciência a uma das faculdades da alma, entendimento, vontade ou sentimento, ou a explica como uma mistura desses elementos" (HEIDEGGER, 2005, p. 57), justamente a noção de Bewusstsein. Na verdade, o filósofo alemão vale-se, isto sim, do termo Gewissen e interpreta-o sob uma nova perspectiva, qual seja: não moral (conhecimento do bem e do mal), mas tão-somente ontológica-existencial (apelo para poder-ser a partir de si mesmo, isto é: existência autêntica).

Heidegger examinou o problema da consciência moral num sentido semelhante ao das outras manifestações da Existência, isto é, de um ponto de vista existencial. A consciência moral é um chamado, um "invocar" que revela à existência sua vocação (Ruf), o que ela é em sua autenticidade. (...) Portanto, a consciência moral é, para Heidegger, um fenômeno existencial que parte da Existência e se dirige à Existência. Em suma, a Existência no fundo de seu estado de "inospitalidade" no mundo é o verdadeiro "vocador da vocação da consciência moral". Por isso, a consciência moral revela-se como o chamado (ou "vocação") do cuidado enquanto ser da Existência. Como a Existência, a consciência moral é sempre a minha; nenhum homem pode pedir auxílio a outro (ou a outros) para determinar qual o chamado ou vocação que lhe é próprio e que se manifesta pelo "dizer silenciando" de sua consciência moral. (MORA, 2000, p. 556)

Em vista disso, quando o presente artigo se refere ao termo "consciência" no caso de Heidegger em seu Ser e tempo, não se trata de modo algum do sentido de reflexão de um "eu" sobre si mesmo (Bewusstsein) e sim de

\footnotetext{
Hamilton, não é suscetível de ser definida, uma vez que designa o aspecto subjetivo e incomunicável da atividade psíquica, de que não se pode conhecer fora do próprio indivíduo, senão as manifestações do comportamento" (PIÉRON, 1972, p. 89). Para Émile Durkheim, consciência está como consciência coletiva que, por sua vez, diz respeito a um arcabouço cultural de ideias morais e convenções normativas. Essa consciência é à parte e externa à vida psicológica dos indivíduos (JOHNSON, 1997, p. 49). Karl Marx, por seu lado, identifica consciência com consciência de classe, a qual designa uma condição social na qual a classe trabalhadora está politicamente consciente - tornando-se, então, classe em si e para si. Por outro lado, a falsa consciência é a ausência dessa condição, levando os trabalhadores, portanto, a terem uma visão ideológica da realidade social (JOHNSON, 1997, p. 49).
} 
uma interpretação existencial da consciência enquanto Gewissen. Assim, nota-se que Heidegger “retira 'consciência' e 'débito' do seu contexto ético em função de um sentido mais fundamental e existencial” (INWOOD, 2002, p. 22). É justamente por se debruçar sobre o sentido de Gewissen e interpretá-lo não moralmente, mas ontologicamente, que Ser e tempo assinala que é através da consciência - ao apelar e, ao mesmo tempo, compreender o clamor desse apelo (Ruf des Gewissens) - que o Dasein, ao querer-ter-consciência, pode ser a partir de si-mesmo, conforme explicitaremos a seguir com maior rigorosidade.

Posto isso, afirma-se que Heidegger propõe-se abordar o fenômeno da consciência em sua investigação puramente existencial, com vistas à sua ontologia fundamental. Esta análise ontológica antecede todas as considerações que a antropologia, a psicologia, a biologia, a teologia e mesmo a interpretação vulgar podem ter acerca da consciência. Neste sentido, é explícita a preocupação metodológica de Heidegger, a qual se exprime em um duplo movimento: por um lado, o autor destaca constantemente a consciência como um fenômeno existencial, que só se anuncia na existência e passível, neste sentido, apenas de análise ontológico-existencial; por outro lado, o autor preocupa-se demasiadamente em diferenciar seu conceito de consciência das problemáticas que são próprias, por exemplo, da psicologia, sociologia, antropologia, biologia ou das teorias baseadas na subjetividade (tais como a do filósofo do cogito). Heidegger (1988, p. 81) considera que tais ciências não visam em absoluto ao Dasein, e sim a regiões específicas do fenômeno em questão, tais como alma, espírito e corpo. Colocando-se como primado frente a essas ciências, a analítica existencial

\footnotetext{
5. Segundo o Dicionário Heidegger: "A 'interpretação ordinária' difere da de Heidegger em quatro pontos: 1. A consciência possui uma função crítica. 2. Ela sempre nos fala de um feito definido que foi realizado ou desejado. 3. A 'voz' da consciência não tem uma relação tão radical com o ser de DASEIN quanto Heidegger supõe. 4. A forma básica da consciência, rejeitada por Heidegger, é a 'má' e a 'boa' consciência, a que censura e a que adverte" (INWOOD, 2002, p. 22).
} 
pretende, com isso, demonstrar a deturpação fundamental que se tem do fenômeno Dasein quando se toma como ponto de partida o princípio de "pessoa", "alma”, "espírito" - em suma, qualquer ponto de partida do subjectum.

Assim, para Heidegger, a consciência "é” e se anuncia tão-somente com e na existência do Dasein: "no contexto problemático desse tratado, a análise da consciência encontra-se unicamente a serviço da questão ontológica fundamental" (HEIDEGGER, 2005, p. 78). A consciência enquanto caractere ontológico por excelência radicado no Dasein é abordado, pelo Heidegger de Ser e tempo, como uma modalidade existencial (Existenzial), assim como todos os caracteres ontológicos enraizados no Dasein, visto que "eles se determinam a partir da existencialidade" (HEIDEGGER, 1988, p. 80). Dasein, enquanto ser-no-mundo, demanda um modo próprio de ser interrogado: trata-se de um quem - existência - e não de um o que - algo simplesmente dado. Este último diferencia-se em modalidades categoriais, as quais dizem respeito às determinações ontológicas dos entes desprovidos do modo de ser do Dasein. Tomar o modo de ser do Dasein como simplesmente dado equivale a renunciar a pergunta pelo sentido de seu ser, tal como fez o filósofo fundador da modernidade ao inaugurar a "subjetividade" (o "sujeito", o "eu") como o grande polo fixo constituinte da verdade (DESCARTES, 1983) ${ }^{6}$.

Entretanto, faz-se necessário, ainda neste item, sinalizar um oportuno adendo. Evidencia-se, por um lado, que Heidegger marca a diferença de seu pensamento com relação à metafísica moderna, em específico, no caso do presente texto, com a cunhagem da noção de consciência em seu Ser e tempo. Porém, isso não significa que ele o faz em detrimento da tradi-

6. Descartes, sim, mas não só: "Num primeiro momento, tem-se a impressão de que Kant abandonou o princípio cartesiano da preexistência de um sujeito isolado. Mas isso não passa de uma impressão. O fato de Kant fornecer uma prova da 'presença das coisas fora de mim' já mostra que, nessa problemática, ele toma o sujeito, o 'em mim', como ponto de apoio” (HEIDEGGER, 1988, p. 270). 
ção metafísica a fim de descartá-la no sentido de errônea.

Em primeiro lugar, as próprias vias interpretativas que Heidegger descartou em sua análise existencial da consciência em Ser e tempo não foram tomadas em nenhum momento como incorretas, falsas ou que devem ser refutadas. Na verdade, o autor as vê, sobremaneira, como derivações do enraizamento ontológico abordado por ele: a análise existencial da consciência:

[...] não possui nenhum direito de desconsiderar a compreensão cotidiana da consciência e passar por cima das teorias antropológicas, psicológicas e teológicas nela assentadas. Caso a análise existencial do fenômeno da consciência tenha liberado o seu enraizamento ontológico, então as interpretações vulgares devem se tornar compreensíveis a partir deste enraizamento e não no seu equívoco e encobrimento do fenômeno. (HEIDEGGER, 2005, p. 78)

Portanto, nota-se, preliminarmente, que as questões familiares a outras interpretações da consciência - antropológica, psicológica, biológica, teológica, vulgar - são de fato válidas, para Heidegger, desde que remetidas adequadamente à raiz originária da consciência enquanto fenômeno ontológico-existencial.

Podemos dizer, além disso, que a noção de consciência ou o termo consciência que Heidegger pretende fundamentar está inserido na sua ontologia fundamental, a qual parte, preliminarmente, da crítica a certas acepções presentes na filosofia tradicional - por exemplo, quanto àquilo que Hegel define por consciência, quanto ao que Marx define por consciência, quanto ao que Descartes define por consciência, Kant, Husserl, etc.

No entanto, o autor não elabora sua noção de consciência, diferenciado-se da tradição, com o propósito de descartá-la no sentido de errônea. Para Heidegger, a metafísica ocidental "é a expressão do próprio destino 
do pensamento" (RESWEBER, 1979, p. 70). Neste sentido, ele não lê os filósofos a partir do exterior para daí os criticar. Pelo contrário: Heidegger, enquanto pesquisador de filosofia, retoma os caminhos já percorridos por esses filósofos da tradição ocidental, ataca-os do interior, mostrando sua insuficiência e, com isso, encontra seus próprios caminhos do pensamento. Como observa Jean-Paul Resweber:

É, pois, da metafísica que é necessário partir para lhe criticar os pressupostos. O pensamento deve interrogar a partir da linguagem constituída da filosofia. É interrogando a metafísica no seu conjunto que o pensador poderá entrever se a filosofia tem verdadeiramente um sentido não-metafísico. (RESWEBER, 1979, p. 70-71)

Quer dizer, vinculando-se à tradição filosófica, já que a ataca por dentro, ao trazer a filosofia de René Descartes à tona, criticando-a em seus fundamentos (ou na falta destes), Descartes é mais do que homenageado - é referido como também capaz de dar voz ao pensar. Heidegger encara a tradição filosófica como a própria expressão de uma visão histórica do Ser. Neste sentido, se é correto que a tradição do pensamento está como tradução da história do Ser, vale sinalizar o caráter historial da própria noção de consciência. Assim sendo, os Seminários de Zollikon (ainda que não contemple o escopo de nosso texto) é oportuno, no sentido de mostrar que o autor reconhece o modo particular como, em cada época determinada, interpretou-se a consciência:

O termo [consciência] é tão antigo quanto a palavra Da-sein e aparece pela primeira vez no século XVIII. A dificuldade de experienciar a consciência está no significado que o tempo proporcionou ao surgimento desta palavra. Onde começa a consciência na filosofia? Em Descartes. [...] Então as palavras "consciente" e "consciência" recebem no século XVIII o sentido teórico como a relação

7. Sobretudo porque extrapola nosso recorte cronológico do pensamento heideggeriano. 
com os objetos experienciáveis. Para Kant recebem o sentido como relação com a natureza como âmbito sensorialmente experienciável. Depois foi dado ainda um passo além: a ciência natural toma esta chamada consciência empírica, este se orientar como a possibilidade da calculabilidade dos processos da física. (HEIDEGGER, 2009, p. 265)

E mais:

Kant também fala da consciência pura. Isto é, aquele conhecer que não se refere mais a objetos empiricamente perceptíveis, mas sim àquilo que possibilita a experienciabilidade dos objetos, ou seja, sua objetidade.

(...) Assim o termo "consciência" tornou-se uma representação fundamental da filosofia moderna. (HEIDEGGER, 2009, p. 266)

Nota-se, com isso, a postura de Heidegger de marcar o caráter historial ou histórico do acontecimento da consciência que, enquanto tal, deve ser pensada junto à história em que surgiu o pensamento. A tentativa de Heidegger superar a metafísica significa, então, levar a reflexão da tradição a superar-se a si própria pela interrogação.

$* * *$

Indo além, parece-nos pertinente nessa fase do texto explicitar com maior alcance de profundidade teórica, por assim dizer, toda a radicalidade que jaz na crítica de Ser e tempo à noção metafísica de consciência, em consonância ao título de nosso trabalho. De acordo com Dicionário de Filosofia, o termo consciência possui, grosso modo, o sentido de: "consideração ou reconhecimento de algo, seja de algo exterior, como um objeto, uma qualidade, uma situação etc., ou de algo interior, como as modificações experimentadas pelo próprio eu" (MORA, 2000, p. 550). Quer dizer, consciência, nessa acepção, diz respeito à percepção (reflexão) de um eu por si mesmo. 
Todavia, Heidegger, em Ser e tempo, não aborda o ente que nós mesmos somos em termos de "eu" que reflete constitutivamente sobre si mesmo, mas sim sob a perspectiva puramente existencial, isto é: o Dasein humano existe no sentido transitivo da palavra.

Em Ser e tempo, Heidegger rejeita o significado do existir em termos de estar "efetivamente presente", que indica ser simplesmente dado (Vorhandenheit) - justamente o que está implicado na acepção (tradicional) da consciência que diz respeito a um "eu" que reflete por si mesmo. Heidegger se vale do termo existência (Existenz) "para designar o ser deste ente [humano]" (HEIDEGGER, 1988, p. 77). Neste sentido, ele utiliza o termo em questão em seu sentido original: "existência" resulta da preposição ek e do verbo sistere, que significa "estar para fora", movimento que parte de dentro para fora; ek-sistir diz respeito ao estar/projetar-se para fora, para exterioridade, expandir para fora. Quer dizer, o filósofo alemão se vale do termo existência em seu sentido transitivo: existindo o Dasein não está simplesmente presente, mas precisa se (fazer) existir, isto é, existir não indica estar-presente mas um movimento - projetar-se para exterioridade -, uma realização; "eu não apenas vivo, mas preciso 'conduzir' minha vida. Existência é um modo-de-ser, e é o ser acessivel para si mesmo [sic]" (SAFRANSKI, 2000, p. 161). Nesse raciocínio, Heidegger afirma que a essência do ente que nós mesmos somos coincide com a existência`, pois tal ente comporta-se com seu ser apenas colocando-o em jogo (em sendo) - "Diferentemente do resto do ente, o ser humano tem uma relação com o seu próprio ser. A isso Heidegger chama existência" (SAFRANSKI, 2000, p. 190) -, o que significa, de alguma forma, que a essência desse ente reside em se

8. "Existência tem um sentido transitivo. Ao instrasitivo no Dasein Heidegger chama o ser-lançado: acaso jamais um Dasein como ele-mesmo decidiu livremente sobre...? Mas quando estamos-aí (intransitivamente), não podemos evitar de viver transitivamente o que é intransitivo em nós. Pelo que nos tornamos intransitivamente, e podemos e temos de ser transitivamente" (SAFRANSKI, 2000, p. 190, grifo do autor).

9. "A 'essência' do Dasein está fundada em sua existência” (HEIDEGGER, 1988, p. 168). 
fazer existir. Mais uma vez: movimento, realização.

Posto isso, é preciso enfatizar que o escopo do presente texto não se propõe a investigar uma nova noção de consciência pensada por Heidegger (uma nova interpretação desse fenômeno), mas o que está em questão é que Heidegger desenvolve uma nova interpretação do ser-aí humano definido essencialmente pelo sentido transitivo da existência - a partir do qual se dá a análise da consciência sob uma perspectiva existencial. Ser e tempo só rejeita a noção de consciência como autorreflexão do "eu" por que o ser-humano, o ser-aí, segundo Heidegger, é interpretado à luz de sua própria existência, isto é, trata-se de um ente que nunca está totalmente acabado, tal como algo simplesmente presente, mas tem que projetar a si mesmo no sentido de se conduzir existencialmente; "Temos de conduzir a nossa vida. Estamos entregue a nós mesmos. Somos aquilo que nos tornamos" (SAFRANSKI, 2000, p. 190). O ser-aí não é não um "eu” corporal-espiritual (exterior-interior) que conhece a si mesmo ou as outras coisas enquanto objetos entre outros dentro do mundo. Neste sentido, é a (nova) interpretação heideggeriana do ser-aí como um ente que se define pela existência que fundamenta a noção, por excelência existencial, de consciência.

Com efeito, destacou-se antes a consciência como fenômeno por excelência existencial. Destaca-se, agora, a consciência radicada fundamentalmente no ser-no-mundo, pois, no limite, ela diz respeito ao movimento pelo qual o Dasein, sendo-no-mundo, pode ser em sentido próprio. Quer dizer, a consciência radica-se no ser-no-mundo na medida em que implica no si-mesmo em sentido próprio enquanto modo de ser-no-mundo. Assim, a consciência enquanto fenômeno constitutivo do ser-no-mundo situa-se 
em outro paradigma: "nem é mais a consciência que na tradição mentalista cartesiana espelha o mundo, nem é, na certeza deste espelhamento, o fundamento do conhecimento deste mundo" (STEIN, 2005, p. 27).

Não obstante, "a análise mais profunda da consciência a desentranha como clamorio " (HEIDEGGER, 2005, p. 54). O apelo da consciência proclama o Dasein para o seu poder-ser-si-mesmo mais próprio. No entanto, em que sentido Heidegger trabalha com a expressão "poder-ser-si-mesmo mais próprio"? Trata-se de um si-mesmo que examina sua "vida interior", tal como se poderia pensar com Descartes? Trata-se de um si-mesmo que medita acerca dos estados da sua "alma"? Manifestamente não. Primeiramente, si-mesmo sequer designa um "sujeito": "isso implica em fixar as questões ontológicas possíveis referentes ao 'si-mesmo' na medida em que ele não é nem substância nem sujeito” (HEIDEGGER, 2005, p. 95). De acordo com Heidegger, deturpa-se o fenômeno do Dasein quando se toma como ponto de partida o princípio de um "eu”, "sujeito", "mente”, "subjetividade”, "pessoa", "alma”, "espírito" ou qualquer propriedade que se possa atribuir ao ser-aí de modo essencial - em suma, qualquer ponto de partida do subjectum.

É interessante observar que, nas raras vezes em que Heidegger, em Ser e tempo, utiliza o termo "eu", com isso ele não pretende se valer do termo enquanto substancialidade. Não se trata de um "eu" entendido "como algo simplesmente dado, já sempre constantemente vigente" (HEIDEGGER, 1988, p. 165), oferecendo, assim, uma base enquanto subjectum (tal qual se dá em Descartes)"11 - pelo contrário: "O simplesmente dar-se em conjunto do físico e do psíquico é, do ponto de vista ôntico e ontológico, inteiramente distinto

10. Embora a tradução da Márcia de Sá que utilizamos em nosso trabalho traduza Ruf como clamor - e seus desdobramentos conclamar, aclamar -, privilegiaremos a palavra português apelar em relação ao termo alemão Ruf.

11. "Aos olhos de Heidegger, a subjetividade é o resultado desta tentativa pela qual o pensamento se exclui da esfera ontológica para por o ser diante dele como um objeto" (RESWEBER, 1979, p. 83). 
do fenômeno do ser-no-mundo" (HEIDEGGER, 1988, p. 271, grifo do autor). Quer dizer, ainda quando a analítica ontológica utiliza a ideia de "eu", realiza-a sempre com reservas de princípio. Heidegger não compreende o "eu" enquanto "sujeito", enquanto aquilo que, a despeito das mudanças de atitude e de vivência, se mantém idêntico e imóvel (que equivaleria à consciência cartesiana). Antes, porém, ao utilizar o termo, Heidegger tem um propósito tão-somente de modalidade existencial: "Para que possa ser uma constituição essencial do Dasein, o 'eu' deve ser interpretado existencialmente" (HEIDEGGER, 1988, p. 168, grifo do autor). Neste sentido, Heidegger faz questão de observar que só a fenomenologia acessa adequadamente o ser do Dasein, na medida que se mantém tão somente em uma demonstração fenomenal orientada pelo modo de ser do próprio ente em questão. Assim, a fenomenologia "preserva-se de toda e qualquer distorção de sua problemática, mesmo frente às respostas mais evidentes e de há muito corriqueiras" (HEIDEGGER, 1988, p. 166). Daí o por que, como diz o próprio autor, não ser "por capricho terminológico que evitamos o uso desses termos bem como das expressões 'vida' e 'homem' para designar o ente que nós mesmos somos" (HEIDEGGER, 1988, p. 82). Para Benedito Nunes (2004, p. 75), Heidegger utiliza a palavra "Dasein", pois esta expressa puramente o ser, neutralizando qualquer ideia prévia de natureza humana.

Em vista disso, Heidegger pretende, com o termo apelo, abordar unicamente o si-mesmo enquanto modo de ser-no-mundo, mais precisamente o modo de ser em sua propriedade. De acordo com Jean-Paul Resweber, "Heidegger distingue dois modos da ek-sistência: a existência inautêntica e a existência autêntica" (RESWEBER, 1979, p. 96). O poder-ser-si-mesmo a que se refere Ser e tempo está sob o ponto de vista tão-somente ontológico-existencial e, enquanto tal, diz respeito ao modo de existir autêntico. Assim sendo, o que no apelo da consciência constitui o "objeto" aclamado? 
O próprio Dasein. E para que perspectiva se apela? Para o poder-ser-si-mesmo em sentido próprio. Vê-se, então, o trânsito ontológico pelo qual a aclamação do apelo é responsável: a passagem de uma situação na qual o Dasein imerge no impessoal (ou seja, nessa condição em que ele procura fugir de si mesmo, não se colocando, portanto, diante de si mesmo), para uma outra condição em que o Dasein coloca-se diante de si mesmo a partir de seu próprio ser.

Com efeito, o apelo da consciência insere um momento de extremo impacto na medida em que o Dasein é convocado a deixar de se perder no domínio da impessoalidade, do qual o Dasein não se dá conta e está no seguinte sentido em Ser e tempo: o Dasein é pulverizado no modo de ser dos outros na medida em que o "a gente", isto é, o impessoal (a impessoalidade) é quem prescreve o modo de ser da cotidianidade. "Este conviver dissolve inteiramente o próprio Dasein no modo de ser dos 'outros' e isso de tal maneira que os outros desaparecem ainda mais em sua possibilidade de diferença e expressão" (HEIDEGGER, 1988, p. 179). Devido ao fato de se colocar como guia prescrevendo e orientando toda deliberação e decisão do Dasein, o "nós", o "a gente", o "bando", retira dele a responsabilidade de ter que assumir seu próprio ser. Com efeito, é justamente nesta perspectiva que, à luz do clamor, se dá um momento de extremo impacto, pois, uma vez que a aclamação "não toma o menor conhecimento de tudo isso" (HEIDEGGER, 2005, p. 58), isto é, não titubeia diante do refúgio e esconderijo da impessoalidade, o Dasein é convocado a deixar de se perder no domínio da impessoalidade. Quer dizer, o sobressalto brusco inserido pelo clamor está no sentido de resgatar o Dasein, por assim dizer, daquilo que vale na convivência pública, e convocá-lo para assumir seu si-mesmo. Ou seja, "o clamor ultrapassa o que o Dasein, de início e na maior parte das vezes, compreende a seu respeito, a partir da interpretação das ocupações" 
(HEIDEGGER, 2005, p. 60). Assim, visto que o clamor constitui "um motivo de ele [Dasein] prestar atenção a si mesmo” (HEIDEGGER, 2005, p. 58), o domínio da impessoalidade - no qual o ser do Dasein é tomado pelos "outros" - sucumbe diante do si-mesmo. E porque sucumbe? Precisamente porque, na aclamação do clamor, a impessoalidade é empurrada para sua devida falta de sentido: "Justamente no ultrapassar [sic], o clamor empurra o impessoal, absorvido nas considerações públicas, para a insignificância" (HEIDEGGER, 2005, p. 58). Neste raciocínio, destaca-se a precisão do comentário: "a consciência, com efeito, obriga-me a abandonar o universo tranquilizador que eu criei para mim, para corresponder à verdade nua da realidade" (RESWEBER, 1979, p. 97, grifo nosso).

Assim, vale reiterar mais uma vez a delimitação que Heidegger traça da consciência enquanto fenômeno existencial, diferenciando-a, portanto, de interpretações - que no máximo, não passam de derivações -, segundo as quais a consciência está no sentido de faculdade da alma, ou entendimento, vontade, sentimento etc. Consciência, no caso de Heidegger, visa recuperar o sentido existencial autêntico do Dasein e, por isso mesmo, o fenômeno em questão é abordado em Ser e tempo como originário: o que ele visa desentranhar é a essência do ser-aí, qual seja, a possibilidade de ser de modo próprio: "o Dasein nunca se pode tornar acessível como algo simplesmente dado porque pertence à sua essência a possibilidade de ser de modo próprio" (HEIDEGGER, 2005, p. 30, grifo nosso). Ou seja, o apelo clama pela ida do Dasein à sua essência: "o Dasein se torna essencial na existência própria” (HEIDEGGER, 2005, p. 117).

Não obstante, a noção de consciência segundo Ser e tempo exprime-se de modo emblemático na seguinte passagem: "O que se busca é um poder-ser próprio do Dasein por ele mesmo, testemunhado em sua possibilidade existenciária” (HEIDEGGER, 2005, p. 52, grifo nosso). Sublinha-se aqui a 
expressão "testemunhado": antes de tudo é preciso que esse testemunho se deixe encontrar pelo Dasein e no Dasein em sua existência própria. Afinal, do que se trata o termo "testemunho"? Para Heidegger, esse termo designa o movimento pelo qual o Dasein, proclamando a si mesmo, direciona-se para o seu poder-ser mais próprio. "O testemunho deve dar a compreender um poder-ser-si-mesmo [sic], em sentido próprio” (HEIDEGGER, 2005, p. 52). O "objeto" do testemunho é justamente o movimento em que o Dasein projeta-se para o modo de existir do si-mesmo em sua propriedade. O que está em jogo com o poder-ser-si-mesmo é a possibilidade de o Dasein assumir seu próprio ser - isto é, encontrar a si mesmo -, e o que é testemunhado no testemunho, neste sentido, é justamente o trânsito em que o Dasein passa da perdição do impessoal para o seu si-mesmo que, como possibilidade, ele já sempre é.

Com efeito, a compreensão do apelar da aclamação desentranha-se para o Dasein como um querer-ter-consciência. Querer-ter-consciência significa prontidão para ser aclamado. "Compreendendo o clamor, o Dasein deixa que o si-mesmo mais próprio aja dentro dele a partir da possibilidade de ser escolhido" (HEIDEGGER, 2005, p. 76, grifos do autor). Com isso, o que está em jogo, direta ou indiretamente, é que o querer-ter-consciência designa (o querer ter) a passagem do próprio-impessoal para o em-si-mesmo. Essa passagem, entretanto, guarda em si uma peculiaridade decisiva: ela deve se cumprir enquanto escolha do Dasein. "A passagem do impessoal, ou seja, a modificação existenciária do próprio-impessoal para o ser-si-mesmo em sentido próprio deve-se cumprir como recuperação de uma escolha" (HEIDEGGER, 2005, p. 53, grifo do autor). Recuperar uma escolha significa escolher e também significa poder-ser-si-mesmo a partir desta decisão. (No domínio da impessoalidade o Dasein não escolhe; "quem" escolhe suas possibilidades são os outros que lhe tomam o ser). Assim, querer-ter-cons- 
ciência é o compreender que contempla a aclamação. Quer dizer, o Dasein possibilita para si mesmo o poder-ser em sua propriedade, em função de escolher essa escolha.

Assim sendo, assinala-se que compreender o que se abre no apelo corresponde a uma compreensão de si em seu poder-ser mais próprio. "Compreendendo o clamor, o Dasein se faz ouvido de sua possibilidade de existência mais própria. Ele escolheu a si mesmo" (HEIDEGGER, 2005, p. 76, grifo do autor). Atender compreensivamente o que se apela na consciência significa escolher se prontificar existencialmente para o poder-ser aclamado, fechando-se, então, para o impróprio do impessoal. "Só é atingido pelo clamor quem se quer recuperar" (HEIDEGGER, 2005, p. 57).

Posto isso, constata-se, por assim dizer: a consciência está existencialmente enraizada no ser-no-mundo na medida em que envolve a passagem do Dasein de seu modo de ser inautêntico para modo de ser autêntico. É através da consciência - ao apelar e ao mesmo tempo compreender o clamor desse apelo - que o Dasein, ao querer-ter-consciência, pode ser a partir de si-mesmo. O que está em jogo com o poder-ser-si-mesmo é a possibilidade de o Dasein assumir seu próprio ser, sendo-no-mundo, portanto, em sentido próprio. Quer dizer, a consciência radica-se no ser-no-mundo na medida em que implica no si-mesmo em sentido próprio enquanto modo de ser do Dasein. Assim, pela consciência, o Dasein testemunha seu trânsito existencial em que passa da perdição do impessoal para o seu si-mesmo.

\section{CONSIDERAÇÕES FINAIS}

Ser e tempo inaugura uma virada paradigmática na história da filosofia: aborda de maneira originária a consciência como fenômeno existencial 
com vistas à sua ontologia fundamental. Enquanto fenômeno puramente existencial, que só se anuncia na existência, a consciência enraíza-se no ser-no-mundo. Isto porque ela implica em um movimento ontológico que diz respeito aos modos de ser-no-mundo: a passagem de um modo em que o Dasein se perde no impessoal, para um outro no qual ele se coloca diante de si mesmo a partir de seu próprio ser. A consciência funda-se no ser-no-mundo, no caso de Heidegger, em seu Ser e tempo, na medida em que ela visa recuperar existencialmente o modo de ser autêntico do ser-aí e, por isso mesmo, Ser e tempo a aborda na condição de fenômeno originário. Uma vez radicada no ser-no-mundo, o que a consciência traz à tona é a possibilidade de o Dasein, sendo-no-mundo, poder-ser-si-mesmo, ou seja, assumir seu próprio ser que equivale a encontrar a si mesmo. Neste sentido, o que é testemunhado no testemunho da consciência é justamente esse trânsito ontológico, em que o Dasein passa da perdição do impessoal para o seu si-mesmo que, como possibilidade, ele já sempre é. 


\section{REFERÊNCIAS}

ABBAGNANO, N. Dicionário de filosofia. 2. ed. Tradução de Alfredo Bosi. São Paulo: Martins Fontes, 1998.

DESCARTES, R. Discurso do Método. 3. ed. São Paulo: Abril Cultural, 1983. Meditações metafísicas. 2. ed. São Paulo: Martins Fontes, 2005.

HEIDEGGER, M. Ser e tempo: parte I. 2. ed. Tradução de Márcia de Sá Cavalcante. Petrópolis: Vozes, 1988.

Ser e tempo: parte II. 12. ed. Tradução de Marcia Sá Cavalcante Schuback. Petrópolis: Vozes, 2005.

Seminário de Zollikon. Tradução de Gabriella Arnhold, Maria de Fátima de A. Prado e Renato Kirchner. Petrópolis: Vozes; Bragança Paulista: Editora Universitária São Francisco, 2009.

INWOOD, M. Dicionário Heidegger. Tradução de Luísa Buarque de Holanda. Rio de Janeiro: J. Zahar, 2002.

JOHNSON, A. Dicionário de sociologia: guia prático da linguagem sociológica. Tradução de Ruy Jungmann. Rio de Janeiro: J. Zahar, 1997.

MANZI, R. O que seria a consciência na fenomenologia heideggeriana? Griot, Amargosa, v. 13, n. 1, p. 183-199, 2016.

MORA, F. Dicionário de Filosofia: tomo I a IV. Tradução de Maria Gonçalves, Adail Sobral, Marcos Bagno e Nicolás Campanário. São Paulo: Loyola, 2000.

NUNES, B. Heidegger \& Ser e tempo. 2. ed. Rio de Janeiro: Jorge Zahar, 2004.

PIÉRON, H. Dicionário de psicologia: publicado com a colaboração da "Association des travailleurs scitifiques". 6. ed. Tradução de Dora de Barros Cullinan. Porto Alegre: Globo, 1972.

RESWEBER, J. P. O Pensamento de Martin Heidegger. Tradução de João Agostinho A. Santos. Coimbra: Livraria Almedina, 1979.

SAFRANSKI, R. Heidegger: um mestre da Alemanha entre o bem e o mal. Tradução de Lya Luft. São Paulo: Geração Editorial, 2000.

STEIN, E. Seis estudos sobre "Ser e tempo". 3. ed. Petrópolis: Vozes, 2005. 